\title{
Paediatrics in Livingston new town: evolution of a child health service
}

\author{
G D STARK, W J BASSETT, D J G BAIN, F I STEWART
}

British Medical fournal, 1975, 4, 387-390

In 1965, a decade before reorganisation of the National Health Service, the Scottish Home and Health Department suggested that an integrated health service experiment be set up in the embryonic new town of Livingston. Its principles were to foster an element of specialisation in general practice, to involve hospital specialists more directly in the community, and to place a new emphasis on preventive medicine. ${ }^{1}$

Since proposals for reorganisation of the child health service in Scotland ${ }^{2}$ embody many concepts that are already a reality in Livingston it seemed appropriate to review our early experience of integration in this field.

\section{Population and resources}

In June 1974 the population of the designated area of Livingston was 21500 and its projected growth rate 4000 a year. Most of its inhabitants have come from Glasgow and the central industrial belt of Scotland. The population is a young one $(39 \%$ under $15,16 \%$ under 5 years), and $40.5 \%$ belong to social classes IV and V.

The Service is based on two health centres in the Craigshill and Howden districts of the town. By the end of 1974 each was serving a population of about 10000 . All 12 general practitioners working from these centres have a specialty interest with an attachment to the district hospital (Bangour General) as medical assistant. Three have a

Department of Child Life and Health, University of Edinburgh, Edinburgh EH9 1UB

G D STARK, DCH, FRCP ED, consultant paediatrician

\section{Livingston, West Lothian}

W J BASSETT, MB, CHB, general practitioner-paediatrician

D J G BAIN, DCH, MD, general practitioner-paediatrician

F I STEWART, DCH, MRCGP, general practitioner-paediatrician special interest in paediatrics in which they have had hospital experience to registrar level. The other specialties concerned-obstetrics, psychiatry, and epidemiology-are geared to the special needs of a new town. To allow time for his hospital commitment and for the development of his specialty in the health centre each doctor's list is restricted to 1500 patients. A consultant paediatrician was appointed to the Livingston area in October 1969 with duties also in the Royal Hospital for Sick Children and the university department of child life and health in Edinburgh.

Each health centre is the base for a community nursing team of six which includes two health visitors, one of whom is particularly concerned with health education. Practice nurses are also employed directly by the general practitioners. A physiotherapist is available for five sessions a week in the well-equipped department of Craigshill health centre and there is a weekly speech therapy session.

A full-time clinical psychologist appointed to Craigshill Health Centre in 1973 provides a direct service to the health centre team which includes assessment and remedial work with children and adolescents. A social worker is attached to the health centres for one session a week in addition to her participation in regular case conferences.

The district hospital provides a comprehensive laboratory and radiology service to general practitioners. More specialised investigation and inpatient treatment of children is provided in the Royal Hospital for Sick Children, Edinburgh.

\section{Preventive paediatrics}

In Livingston preventive services, including those which were formerly the responsibility of the local authority health departments, are regarded as an integral part of primary care of children.

Routine primary immunisation has been achieved in $95 \%$ of the preschool child population, appointments being made and patients notified by computer. Immunisations are carried out by health visitors, but a general practitioner-paediatrician is always available to advise in cases of doubt.

$A$ well-baby clinic is held weekly by the health visitors, to which mothers can come without appointment for advice on infant feeding, growth and development, and the minor problems of childhood.

Routine developmental screening of children in the first five years of life is carried out. The original plan for seven examinations proved 
overambitious in view of the unusually large proportion of children in the population. Screening is now carried out at 6 weeks, 10 months, 2 years, and $4 \frac{1}{2}$ years, the last to serve as a school entry examination. In one health centre each general practitioner is responsible for screening of children registered with him; in the other all developmental screening is done by two general practitioner-paediatricians who are attempting a critical evaluation of the programme. In Craigshill Health Centre in 1972 the attendance rate for developmental screening was $70-80 \%$ and children failing to attend on two occasions were seen by a health visitor. A total of 1200 examinations led to the detection of 96 children with doubtful developmental progress or moderately severe physical conditions requiring treatment or followup. In addition, six children were found to have unsuspected major abnormalities (two with serious failure to thrive and one each with congenital dislocation of the hip, Werdnig-Hoffman disease, partial hearing, and auditory imperception). The value of routine developmental screening requires further study over a longer period of time, but there is no doubt of the value of these clinics in educating parents in child care and development.

\section{Clinical paediatric services}

Primary care-All Livingston practitioners provide primary care for both children and adults registered with them. A 24-hour service is provided from each health centre and self-referral to hospital casualty departments is actively discouraged. Of all items of services provided $35 \%$ are for children.

The commonest problems are listed in table $\mathrm{I}$, which shows the kind of data that can be retrieved by the computer recording of morbidity in general practice. ${ }^{3}$ Infective diseases and respiratory and neurological disorders were over-represented in children in relation to their proportion of the total population.

TABLE I-Frequency of most common presenting conditions in Livingston 1971 and 1972

\begin{tabular}{|c|c|c|c|c|c|}
\hline & \multirow[t]{2}{*}{$\begin{array}{l}\text { ICD } \\
\text { Codes }\end{array}$} & \multicolumn{2}{|c|}{$\begin{array}{l}\% \text { of all child } \\
\text { consultations }\end{array}$} & \multicolumn{2}{|c|}{$\begin{array}{c}\text { Child } \\
\text { consultations as } \\
\% \text { of all } \\
\text { consultations* }\end{array}$} \\
\hline & & 1971 & 1972 & 1971 & 1972 \\
\hline $\begin{array}{l}\text { Respiratory system diseases } \\
\text { Infective and parasitic disease } \\
\text { Diseases of central nervous }\end{array}$ & $\begin{array}{l}460-519 \\
000-136\end{array}$ & $\begin{array}{l}33 \cdot 8 \\
13 \cdot 4\end{array}$ & $\begin{array}{l}32 \cdot 4 \\
15 \cdot 2\end{array}$ & $\begin{array}{l}50 \cdot 6 \\
50 \cdot 2\end{array}$ & $\begin{array}{l}46 \cdot 8 \\
54 \cdot 5\end{array}$ \\
\hline $\begin{array}{l}\text { system and sense organs } \\
\text { Symptoms and ill-defined con- }\end{array}$ & $320-89$ & $10 \cdot 7$ & $12 \cdot 1$ & $46 \cdot 1$ & $44 \cdot 2$ \\
\hline $\begin{array}{l}\text { ditions } \\
\text { Skin and subcutaneous tissue }\end{array}$ & $780-96$ & $12 \cdot 2$ & $10 \cdot 2$ & $33 \cdot 5$ & $31 \cdot 4$ \\
\hline $\begin{array}{lll}\text { diseases } & & \\
\text { Mental disorders } & \ldots & \cdots\end{array}$ & $\begin{array}{l}680-709 \\
290-325\end{array}$ & $\begin{array}{l}8 \cdot 1 \\
4 \cdot 9\end{array}$ & $\begin{array}{l}8 \cdot 5 \\
4 \cdot 1\end{array}$ & $\begin{array}{l}35 \cdot 3 \\
11 \cdot 9\end{array}$ & $\begin{array}{l}35 \cdot 9 \\
10 \cdot 8\end{array}$ \\
\hline violence $\ldots$ & $\begin{array}{l}\text { E800-999 } \\
\text { N800-999 }\end{array}$ & $4 \cdot 3$ & $4 \cdot 9$ & $24 \cdot 8$ & $24 \cdot 5$ \\
\hline
\end{tabular}

*Children under 15 constituted $39 \%$ of population at risk.

Treatment room service-Practice nurses in Craigshill Health Centre are responsible for a treatment room service. ${ }^{4}$ In 1972 children under the age of 15 years accounted for 3000 attendances and made up $46 \%$ of its clientele. Skin complaints $(41 \%)$, minor injuries $(37 \%)$, and disorders of the eyes, ears, nose, and throat $(5 \%)$ were pre-eminent. The easy availability of this service has led to a decline in self-referral of children to hospital by their parents. Included among the duties of the practice nurse is follow-up treatment of children discharged from surgical wards and diagnostic procedures such as urine testing, electrocardiogram recording, and audiometry.

Specialty paediatric services-A more specialised service is provided in each health centre by the consultant and general practitionerpaediatricians. There is ample justification for this in the fact that $10 \%$ of all Livingston children need continuing medical supervision (table II). In two-thirds of these children in 1972 the reason was a "psychological" or "psychosomatic" problem such as behaviour disorder, enuresis, or asthma. In each centre a weekly paediatric clinic is held by the GP-paediatrician in which he sees children referred by health centre colleagues or from hospital for local follow-up. In one health centre in 1972 there were 115 new referrals and 288 children were reviewed. Most of these patients could be satisfactorily managed by the general practitioner-paediatricians. Only $15 \%$ of new patients required referral to the consultant, who holds a monthly clinic in each health centre. This clinic, which is also attended
TABLE II-Need for continuing medical attention in children. Figures are taken from a child population at risk of 3555 at Craigshill Health Centre, fuly 1972

\begin{tabular}{|c|c|c|c|c|c|}
\hline & & \multicolumn{3}{|c|}{ Age } & \multirow{2}{*}{$\begin{array}{l}\text { Prevalence } \\
\text { per } 1000\end{array}$} \\
\hline & & $\leqslant 4$ years & $5-14$ years & Total & \\
\hline $\begin{array}{l}\text { Mental subnormality } \\
\text { Blind/partial sight } \\
\text { Deaf/partial hearing } \\
\text { Cerebral palsy/spina bifida } \\
\text { Significant orthopaedic disease } \\
\text { Dwarfism and complicating } \\
\text { anomalies } \\
\text { Congenital heart disease } \\
\text { Cystic fibrosis } \ldots \\
\text { Coeliac disease } \ldots \\
\text { Juvenile diabetes mellitus } \\
\text { Epilepsy . } \\
\text { Neoplasm } \\
\text { Behaviour disturbance . } \\
\text { Asthma and asthma/eczema } \\
\text { Enuresis (over 5 years) ... }\end{array}$ & $\begin{array}{l}\cdots \\
\cdots \\
\cdots \\
\cdots \\
\cdots \\
\cdots \\
\cdots \\
\cdots \\
\cdots\end{array}$ & $\begin{array}{r}4 \\
1 \\
3 \\
6 \\
4 \\
2 \\
2 \\
3 \\
2 \\
0 \\
3 \\
0 \\
28 \\
24\end{array}$ & $\begin{array}{r}32 \\
3 \\
13 \\
5 \\
6 \\
0 \\
4 \\
0 \\
5 \\
1 \\
10 \\
1 \\
53 \\
44 \\
89\end{array}$ & $\begin{array}{r}36 \\
4 \\
16 \\
11 \\
10 \\
2 \\
6 \\
3 \\
7 \\
1 \\
13 \\
1 \\
81 \\
68 \\
89\end{array}$ & $\begin{array}{r}10 \cdot 0 \\
1.1 \\
4 \cdot 4 \\
3 \cdot 1 \\
2 \cdot 8 \\
0.6 \\
0.7 \\
1.7 \\
0.8 \\
1.9 \\
0.3 \\
3 \cdot 6 \\
0.3 \\
22.5 \\
18.9 \\
24 \cdot 7\end{array}$ \\
\hline Total & & 82 & 266 & 348 & $96 \cdot 7$ \\
\hline
\end{tabular}

by the physiotherapist, psychologist, and a general practitioner deals mainly with the more complex neurodevelopmental problems.

Referral rates-The impact of the internal referral system and consultant clinics in the health centres is evident from table III, which shows the numbers attending hospital outpatient clinics in 1971 and 1972. Most referrals were for surgical and ear, nose, and throat conditions. The overall outpatient referral rate for 1972 of 34.2 per 1000 was about half that estimated for a population of comparable size by Carstairs and Howie ${ }^{5}$ and compares even more favourably with the results of a survey carried out in south-east Scotland in 1961, which showed that 170 per 1000 children attended hospital outpatient departments in a year. ${ }^{6}$ In Livingston in $19721.6 \%$ of children's consultations were followed by hospital outpatient referral. By contrast, $10 \%$ of children in south-east England were so followed, ${ }^{7}$ and in Newcastle $17 \%$ of children seen by general practitioners were referred to hospital. ${ }^{8}$ Most medical paediatric referrals from Livingston are to regional clinics dealing with such specialties as child psychiatry, cardiology, cystic fibrosis, metabolic disorders, spina bifida, cerebral palsy, and hearing defects. Paediatric supervision in the health centres may, however, reduce the need for many such patients to attend Edinburgh clinics more than once a year.

TABLE III-Hospital outpatient referrals of children according to specialty from Craigshill Health Centre in 1971-2

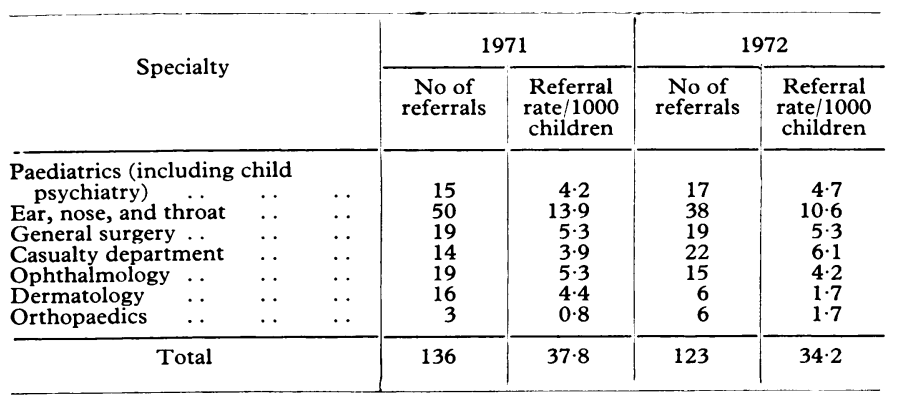

\section{Hospital role of the general practitioner-paediatrician}

Although each general practitioner-paediatrician has five nominal sessions as medical assistant in paediatrics, rigid separation of "hospital" and "community" work has been avoided. At present the absence of a children's ward in the district hospital restricts the inpatient role of the general practitioner-paediatrician to the neonatal unit, which provides care for 1800-2000 infants each year.

With the consultant paediatrician and a paediatrician from the department of community medicine, one of the general practitioners takes part in a weekly follow-up clinic for infants discharged from the special care nursery. Another helps the consultant in the general paediatric clinic, which serves the West Lothian district outside Livingston new town. This close working relationship in hospital clinics and neonatal ward rounds facilitates discussion of both hospital and health-centre patients by the general practitioner and consultant paediatricians. 


\section{Paediatric teaching and research}

The important teaching and research potential of the Livingston project has not yet been fully exploited. During their final-phase attachment in paediatrics, Edinburgh University students are offered a visit to Livingston as well as a longer elective period, options which are being taken up with increasing frequency. Students are given a clear appreciation of the wide field of child health which extends beyond the hospital walls and a glimpse of the kind of practice based on a health centre in which many of them may later work. The response has been enthusiastic. Most teaching in the health centres is, however, devoted to vocational trainees, nursing staff, and postgraduate visitors.

Research has so far been of a predominantly operational variety. Nevertheless, the child health service offers scope for rewarding study of more basic developmental, social, and clinical aspects of paediatrics.

\section{Discussion}

Even in an integrated health service there will always be two distinct groups of doctors: those working mainly in hospital and those working mainly in the community. The Livingston experiment has, however, shown that there need be no sharp distinction between the two and that the greater mutual understanding that results can only be to the patients' benefit. Experience in Livingston has heightened the consultant paediatrician's awareness of the poverty of communication-almost entirely by letter-with other family doctors in the area served by the regional children's hospital.

In setting down the following opinions on the viability of the main concepts of the Livingston child health service, the scope for further development, and the application to other areas we are aware of the need for a more objective audit of paediatric care in Livingston and for comparative studies elsewhere.

\section{PAEDIATRIC SPECIALISATION IN GENERAL PRACTICE}

The degree of general-practitioner specialisation in Livingston is intermediate between conventional general practice and the more extreme concept of McKeown, ${ }^{9}$ who stated that "since it is no longer possible for one person to maintain clinical competence in the care of all age groups, the best arrangement would be to divide medical responsibility according to age groups." In a new town with a young population paediatrics has proved to be one of the specialties which can be combined most happily with general practice.

The internal referral system in the Livingston health centres has greatly reduced the frequency of hospital referral, with consequent sparing of inconvenience, anxiety, and expense for parents. By advising his fellow practitioners on management of their child patients, there is little doubt that the general practitioner-paediatrician can enhance the overall standard of paediatric practice in his health centre. Conversely, contact with other general practitioner specialists helps maintain his clinical skills in other aspects of medicine.

We believe that in the average group practice or health centre of six doctors there is scope for one to develop a special interest in paediatrics. In larger centres a case can be advanced for a measure of specialisation within paediatrics. In Livingston, for example, one general practitioner-paediatrician has developed a special interest in the handicapped child, another in diagnostic and therapeutic paediatrics, and the third in social and epidemiological aspects of child health. For others the chosen field might be educational medicine, developmental screening, or one of the paediatric subspecialties such as ear, nose, and throat conditions or dermatology. Specialisation to this degree, however, implies provision of a service beyond the confines of his own health centre, which could present greater problems in other areas than is likely in Livingston.

\section{THE GENERAL PRACTITIONER-PAEDIATRICIAN'S ROLE}

There is less certainty about the hospital role of the general practitioner-paediatrician than about his place in the health centre. Whatever his previous paediatric training and experience there is no doubt that he should have continuing and close contact with the district and regional paediatric service. Although the report General Practitioners in the Hospital Service ${ }^{10}$ takes a sanguine view of the maiter, there are important limits to employment of general practitioners in hospital paediatrics. Their hospital role should be chosen carefully so that it is both relevant to their work in general practice and can be fulfilled more effectively by them than by conventional hospital staff. Generally the present neonatal commitment of the Livingston general practitioner-paediatricians falls short of these criteria in that the urgent demands of a special care baby unit may easily conflict with primary care duties. Conversely, a registrar could be more readily available and provide greater continuity in patient care and support for resident staff.

While the possibility of deployment of the general practitionerpaediatrician in a general paediatric unit is not excluded fewer difficulties are seen with his involvement in outpatient work. In narrow fields such as speech disorders or asthma he might develop considerable expertise and provide long-term continuity of staffing which would be impossible with the registrar grades.

\section{CONSULTANT PAEDIATRICIAN IN THE HEALTH CENTRE}

Marsh and Tompkins ${ }^{11}$ have described paediatric consultation in a health centre serving a population of 15000 in Stocktonon-Tees. Though none of their patients lived more than four miles from the children's hospital the outstanding advantage was seen as convenience for parents. The familiar informal surroundings of the health centre and the presence of the family doctor were reassuring for children and their mothers. In Livingston, where few families live within 15 miles of the Royal Hospital for Sick Children, the advantages are similar. Expenditure of one hour of travelling by the consultant can spare possibly 18 hours of travel, inconvenience, and anxiety for the children and their parents. Their appreciation is reflected in the high attendance rate: contrary to the experience of Harper et al ${ }^{12}$ with gynaecological clinics in Woodside Health Centre in Glasgow, appointments were more often kept in Livingston than in the corresponding hospital clinics in Edinburgh. In the health centre the child is often easier to examine and the complete general practice record is available. The consultant's opinion can be conveyed at once to the general practitioner-paediatrician, who also knows exactly what has been said to the motherinformation commonly lacking in consultants' letters from hospital.

\section{Conclusions}

Reorganisation has brought the possibility, but not the certainty, of a more integrated and effective child health service. In future the principal function of the paediatric unit should be provision of intensive care for the severely ill child and comprehensive investigation and assessment of children with more obscure or complex problems. Preventive paediatrics, formerly a local authority responsibility, should increasingly be accepted as an integral part of primary care. Our experience in Livingston suggests that not only is this possible but that a higher proportion of disability and illness in childhood can be managed in the community given modern health centre facilities and greater paediatric skill in general practice. Paediatric specialisation does not depend on hospital sessions for the interested practitioner but does require a close supportive relationship with the children's hospital. The development of the child health service in Livingston must of necessity continue. Many questions remain and difficulties have still to be overcome. Nevertheless, the thesis that the major part of child health care can be provided by the primary care system has, we believe, been confirmed. 
We acknowledge the co-operation of our fellow practitioners and their secretaries and, in particular, the invaluable work of Mrs Helen Mehta in organising clinics and collecting data. We thank Mrs E Pay for secretarial help.

\section{References} \\ 1 Duncan, A H, Health Bulletin, 1970, 28, 54. \\ 2 Scottish Home and Health Department, Towards an Integrated Child \\ Health Service. Edinburgh, HMSO, 1973. \\ ${ }^{3}$ Gruer, K T, and Heasman, M A, British Medical fournal, 1970, 2, 289. \\ 4 Bain, D J G, and Haines, A J, Health Bulletin, 1974, 32, 11.
}

${ }^{5}$ Carstairs, V, and Howie, V, Health Service in Population of 250,000. Scottish Health Service Studies No 24. Edinburgh, SHHD, 1972.

${ }^{6}$ Forfar, J O, and Arneil, G C, Textbook of Paediatrics. Edinburgh, Churchill Livingstone, 1974.

7 Joseph, M, and MacKeith, R C, A New Look at Child Health. London, Pitman Medical, 1966.

${ }^{8}$ Miller, F J W, et al, Growing up in Newcastle upon Tyne: A continuing study of health and illness in young children within their families. London, Oxford University Press for the Nuffield Foundation, 1960.

${ }^{9}$ McKeown, T, Medicine in Modern Society. London, Allan and Unwin, 1965.

10 Scottish Home and Health Department, General Practitioners in the Hospital Service. Edinburgh, HMSO, 1973.

${ }^{11}$ Marsh, G N, and Tompkins, A B, British Medical fournal, 1969, 2, 106.

12 Harper, W F, Auld, A, and Murray, A, Health Bulletin, 1972, 31, 281.

\title{
Peripheral paediatric clinics: survey and medical audit
}

\author{
S D V WELLER
}

British Medical fournal, 1975, 4, 390-393

\begin{abstract}
Summary
The work of the paediatric clinics in nine generalpractitioner hospitals in country towns in the Bath Health District during 1972 was analysed with respect to the pattern of referrals and methods of management. It is concluded that no child suffered harm from being seen in a clinic without full laboratory and $x$-ray facilities. Nearly $98 \%$ of the consultations were deemed, even with a long period of hindsight, to have been completely satisfactory. The tremendous benefit to the patients and their families of being seen in a hospital near their home is not bought at the cost of a second-rate medical service.
\end{abstract}

\section{Introduction}

In a comparison of paediatric clinics held in the general hospital in Bath with those held in country towns in the district, patients expressed a strong preference for the latter, peripheral clinics on the grounds of cost and convenience. ${ }^{1}$ The important consideration, however, is the standard of care offered. It would be a poor gain to save the patient trouble and cash if the quality of care he receives is reduced. Marsh and Tompkins ${ }^{2}$ reviewed the work of a clinic conducted by a consultant paediatrician at a group practice over 18 months; the family doctor was usually present. They felt that there were advantages to both the doctors and patients and that such consultations were medically adequate. Gruer ${ }^{3}$ commented on a large number of consultations in southern Scotland that entailed only a single visit, with no review, which were clearly deemed satisfactory despite the lack of special facilities.

Recently the need for some investigations that had been regarded as mandatory has been questioned, ${ }^{4}$ and Leonard et $a l^{5}$ pointed out the small contribution to diagnosis made by a biochemical profile in nearly 3000 children. Any paediatrician who regards a full blood count, chest $x$-ray examination, and serum chemistry as part of the routine clinical examination of every child would consider any consultation without even the possibility of these tests as grossly inadequate. I therefore

Bath Health District

S D V WELLER, MD, FRCP, consultant paediatrician declare myself as one who has tended over the years to do fewer investigations and who is no longer upset at the prospect of conducting some clinics in what is kept to look like an ordinary room. There is no white coat, and diagnostic instruments are kept out of sight.

In the Bath Health District (population 350000 ) three peripheral clinics are conducted each week by a consultant paediatrician. Any child from a country clinic who needs investigations is admitted to the ward in the general hospital in Bath on a day-patient basis to avoid an overnight stay.

\section{Present study}

In view of the difficulty of comparing the work of different consultants or asking one colleague to check the performance of another I studied the quality and efficiency of consultations in the country clinics by following up children seen in 1972 by one consultant. My aim was to see whether the care offered had seemed adequate at the time and whether it had proved to be as satisfactory in the light of subsequent progress. Data were collected on every consultation during the year at clinics conducted in nine peripheral hospitals, which I visited. Information was gathered on the later course of the problem for which the child was referred.

Often it was easy to say whether or not the decision made had proved correct. When there was doubt or when the child had been discharged from the clinic the family doctor was asked for particulars; he was specifically asked whether he had thought at the time that the consultant's action was right and whether events had made him revise this view. In a few instances the parents were asked for information and even to give their opinions.

In 1972 study leave and illness prevented me from doing these clinics for a total of 18 weeks. The survey therefore covers not only my performance but also that of four other specialists who undertook. locum work.

The nine hospitals were usually visited monthly; occasionally clinics were cancelled because of national holidays or leave. When demand was increased extra clinics were arranged.

\section{BOOKINGS AND ATTENDANCES}

Altogether 101 clinics were held, with an average of 11 patients booked per session (table I). There were 27 defaulters among the new patients and 53 among the old ones; this latter figure includes patients who defaulted more than once, whose families were usually known to the social services. Defaulters among new referrals were mainly cases referred from the wards for a check on their progress since discharge.

Actual attendances are shown in table I. New patients are separated into direct referrals from family doctors and those whose visit had been requested by the ward to ensure that the child who had been sent home before complete recovery, perhaps for social reasons, had 